\title{
The assessment of combined first trimester screening in women of advanced maternal age in an Asian cohort
}

\author{
Sarah Weiling $\underline{\mathrm{Li}}^{1, *}$, MBChB, BSc, Angela Natalie Barrett $^{2, *}$, PhD, Leena Gole ${ }^{3}$, PhD, Wei Ching $\underline{\text { Tan }}^{4}$, MBBS, FRCoG,
} Arijit Biswas ${ }^{1}$, MD, FRCOG, Hak Koon ${\underline{\text { Tan }^{4}}}^{\text {, MRACOG, FRCOG, Mahesh Choolani }}{ }^{2}$, FRCoG, PhD

INTRODUCTION First trimester screening (FTS) is a validated screening tool that has been shown to achieve detection rates of $84 \%-90 \%$ for trisomies 21,18 and 13 . However, its effectiveness for different maternal ages has not been assessed. The present study aimed to assess the performance of FTS in an Asian population, and to compare its effectiveness in older ( $\geq 35$ years) and younger ( $<35$ years) women. The potential use of noninvasive prenatal test (NIPT) as a contingent screening test is also examined.

METHODS Data on cases of FTS performed on singleton pregnancies over a six-year period was collated from two Singapore maternal centres, National University Hospital and Singapore General Hospital. Cases that had a 1:250 risk of trisomy were considered to be screen-positive. Pregnancy outcomes were obtained from birth records or karyotype test results. RESULTS From 10,289 FTS cases, we obtained a sensitivity of $87.8 \%$, a specificity of $97.6 \%$, a false positive rate of $2.4 \%$ and a false negative rate of $0.06 \%$ for the detection of aneuploidy. The overall detection rate for trisomy 21 was $86.5 \%-85.7 \%$ for older women and $87.5 \%$ for younger women. The mean number of invasive tests required per case of trisomy 21 was 9.3 in younger women, 8.6 in older women and 13.5 in women with intermediate risk (1:250-1,000). CONCLUSION While the performance of FTS was similar in younger and older women, more invasive procedures were required to diagnose trisomy 21 in women with intermediate risk. It may be advantageous to offer contingent NIPT to this group of women to reduce the risk of iatrogenic fetal loss.

Keywords: cell-free fetal DNA, Down syndrome, first trimester screening, noninvasive prenatal testing

\section{INTRODUCTION}

First trimester screening (FTS) is a validated screening modality for major chromosomal aneuploidies (i.e. trisomies 21,18 and 13)..$^{(1-3)}$ Using a combination of maternal age, fetal nuchal translucency thickness, maternal levels of serum free $\beta$-human chorionic gonadotropin ( $\beta$-hCG) and pregnancy-associated plasma protein $\mathrm{A}$ (PAPP-A), FTS has been shown to achieve a detection rate of $84 \%-$ $90 \%$, with a false positive rate of $5 \% .^{(4-6)}$ Although FTS has been adopted in many countries as the first-line screening for trisomy 21 (i.e. Down syndrome), its effectiveness in women of different ages has not been adequately assessed. A recent observational study reported that FTS is less effective in women aged $<35$ years and that a greater number of invasive procedures needs to be performed in this group of women to diagnose a case of trisomy $21 .^{(7)}$ This finding is contrary to reports on other Caucasian populations. ${ }^{(8-10)}$

If the performance of FTS varies in women of different ages, it is clinically pertinent that these variations are understood. This is especially since the proportion of pregnant women of advanced maternal age, defined as age 35 years and above in most countries, has increased in the past decade. It is unclear whether the widely published detection rates in the literature can be universally applied to women of all ages, especially those of advanced maternal age, as they appear to have a higher risk for fetal trisomy 21.

There has been a growing body of evidence regarding the high negative predictive value of noninvasive prenatal testing
(NIPT) using cell-free DNA (cfDNA) and its potential to reduce iatrogenic fetal loss. ${ }^{(11-14)}$ Several countries have already started to recommend the use of NIPT using cfDNA for contingent screening in women who are at a higher risk of a fetus with trisomy 21 , including women of advanced maternal age. ${ }^{(15-18)}$ There is, however, a lack of information regarding the potential incremental costs that follow contingent screening, especially in Singapore.

The objectives of the present study were to assess the performance of FTS in an ethnically mixed population for the detection of fetal trisomy 21, and to compare the effectiveness of FTS in women of advanced maternal age (i.e. $\geq 35$ years) with that of FTS in women aged $<35$ years. We also aimed to determine the incremental cost of detecting one case of trisomy 21 if NIPT was offered to all women who had intermediate- or high-risk scores following FTS.

\section{METHODS}

The data used in the present study was derived from two tertiary maternity centres in Singapore - National University Hospital (NUH) and Singapore General Hospital (SGH). All cases of FTS performed in these two centres between January 2006 and December 2011 were collated. At both institutions, FTS was strictly performed between $11+0$ and $13+6$ weeks of gestation, according to the guidelines established by the Fetal Medicine Foundation (FMF), United Kingdom. ${ }^{(19)}$ All ultrasound

${ }^{1}$ Department of Obstetrics and Gynaecology, National University Hospital, ${ }^{2}$ Department of Obstetrics and Gynaecology, National University of Singapore, ${ }^{3}$ Department of Laboratory Medicine, National University Hospital, ${ }^{4}$ Department of Obstetrics and Gynaecology, Singapore General Hospital, Singapore

*These two authors contributed equally as first author in this work.

Correspondence: Prof Mahesh Choolani, Associate Professor and Senior Consultant, Department of Obstetrics and Gynaecology, National University of Singapore, NUHS Tower Block, Level 12, 1E Kent Ridge Road, Singapore 119228. obgmac@nus.edu.sg 


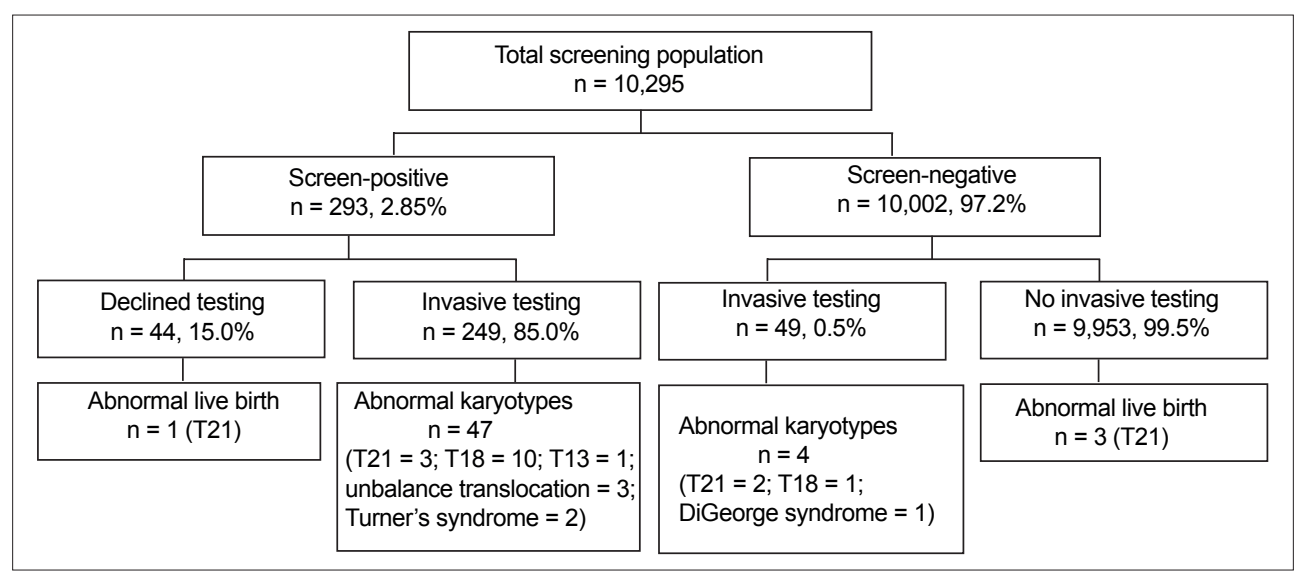

Fig. 1 Outcome of the cases that underwent first trimester screening, in National University Hospital and Singapore General Hospital, from 2006-2011.

assessments of fetal crown-rump length, NT and nasal bone were performed by sonographers who had achieved the appropriate FMF Certificate of Competence. The risks for trisomies 21, 18 and 13 were calculated using an algorithm provided by the FMF. At $\mathrm{NUH}$, karyotyping by amniocentesis or chorionic villus sampling is advised when the FTS risk is 1:250 and above, while at $\mathrm{SGH}$, karyotyping is advised when the risk is 1:300 and above. These patients are considered to be 'high risk'.

The final study population included only singleton pregnancies and cases in which the pregnancy outcome was known (either via karyotype test results or birth records). All cases were classified as either screen-positive or screen-negative. In the present study, screen-positive cases were identified as those that had a risk greater than 1:250 for trisomy 21,18 or 13 ; this criteria was used for all eligible patients. We did not observe any significant difference in the number of invasive procedures performed at the centre that used a cut-off value of $1: 300$ (i.e. SGH) and the centre that used a cut-off of 1:250 (i.e. NUH). The karyotype test results of all cases where invasive testing was performed were known, as were the delivery outcome of all cases where invasive testing was declined. If a patient was classified as screen-negative after FTS, her status would not be altered even if she opted for elective invasive testing or if invasive testing was performed based on soft ultrasound markers. This is analogous to an intention-to-treat analysis. All delivery outcomes in the screen-negative group were known.

The overall sensitivity, specificity, positive predictive value (PPV) and negative predictive value (NPV) of FTS using the risk cut-off value of 1:250 was calculated and compared to its performance when different risk cut-off values were applied. We also compared the performance of FTS for women aged $<35$ years and women aged $\geq 35$ years at the risk cut-off value of $1: 250$. To calculate the incremental cost per case of trisomy 21 detected by NIPT, we tabulated the cumulative number of cases screened positive and the number of trisomy 21 cases detected at different risk cut-off values. The cost of NIPT in Singapore was estimated to be around $S \$ 1,000$. Statistical analysis was performed using the MedCal software (http://www.medcalc.org/calc/diagnostic_ test.php) and the Statistical Package for the Social Sciences version 22.0 (SPSS Inc, Chicago, IL, USA).

\section{RESULTS}

A total of 10,295 cases of FTS were identified after the inclusion criteria were applied. The ethnicity of the study population was predominantly Chinese and Southeast Asian ( $n=9,604,93.3 \%$ ) and the mean maternal age was $31.6 \pm 4.3$ (range 16-47) years. Of the 10,295 women, 2,682 (26.1\%) were aged $\geq 35$ years. The median gestational age at which FTS was performed was $12+4$ (range $11+0$ to $13+6$ ) weeks.

The outcome of all cases that underwent FTS is summarised in Fig. 1. There was a total of 49 cases of trisomy (37 cases of trisomy 21, 11 cases of trisomy 18 and 1 case of trisomy 13), giving rise to a prevalence of 4.8 trisomies per 1,000 cases. The prevalence of trisomy 21 in the present study was 3.6 per 1,000 cases. When a risk cut-off value of 1:250 was applied, 293 of the 10,295 cases (2.85\%) were screen-positive. Among these 293 women, 249 (85.0\%) underwent invasive diagnostic testing, while 44 (15.0\%) declined further testing. Among the 249 cases that had invasive testing, abnormal karyotypes were returned in 47 cases (31 cases of trisomy 21, 10 cases of trisomy 18, 1 case of trisomy 13 and 5 cases of other chromosomal abnormalities). The five other chromosomal abnormalities were unbalanced translocations ( $n=3)$ and Turner's syndrome $(n=2)$; these five cases were excluded from the final analysis, thus resulting in a sample size of 10,290 cases. One patient from the screen-positive group who declined invasive testing gave birth to a child with confirmed trisomy 21 . The total number of false positive cases was 245 .

In our study population, 49 of the 10,002 screen-negative cases chose to undergo elective invasive testing. The majority of these 49 cases were motivated to undergo elective invasive testing due to the presence of soft ultrasound markers. Among these 49 cases, abnormal karyotypes were returned in four cases (two cases of trisomy 21, one case of trisomy 18 and one case of DiGeorge syndrome). There were three live births affected with trisomy 21 that were undetected by FTS, giving rise to a total number of six missed trisomies (i.e. false negative) - five trisomy 21 and one trisomy 18 . Four of these six babies were born to mothers aged $\geq 35$ years and two to mothers aged $<35$ years. One miscarriage occurred after amniocentesis and this occurred in a screen-positive patient (the fetus had DiGeorge syndrome). 
Table I. Performance of first trimester screening in detecting trisomies 21, 18 and 13 at different selected risk cut-offs $(n=10,289)$.

\begin{tabular}{|c|c|c|c|c|c|c|c|c|}
\hline \multirow{2}{*}{$\begin{array}{l}\text { Risk } \\
\text { cut-off }\end{array}$} & \multicolumn{4}{|c|}{ Absolute numbers } & \multicolumn{4}{|c|}{$\%$ (95\% confidence interval) } \\
\hline & $\begin{array}{c}\text { True } \\
\text { positive }\end{array}$ & $\begin{array}{c}\text { False } \\
\text { positive }\end{array}$ & $\begin{array}{c}\text { True } \\
\text { negative }\end{array}$ & $\begin{array}{c}\text { False } \\
\text { negative }\end{array}$ & Sensitivity & Specificity & PPV & NPV \\
\hline $1: 100$ & 34 & 133 & 10,107 & 15 & $\begin{array}{c}69.39 \\
(54.58-81.74)\end{array}$ & $\begin{array}{c}98.70 \\
(98.47-98.91)\end{array}$ & $\begin{array}{c}20.36 \\
(14.53-27.27)\end{array}$ & $\begin{array}{c}99.85 \\
(99.76-99.92)\end{array}$ \\
\hline $1: 150$ & 39 & 174 & 10,066 & 10 & $\begin{array}{c}79.59 \\
(65.65-89.74)\end{array}$ & $\begin{array}{c}98.30 \\
(98.03-98.54)\end{array}$ & $\begin{array}{c}18.31 \\
(13.36-24.17)\end{array}$ & $\begin{array}{c}99.90 \\
(99.82-99.95)\end{array}$ \\
\hline $1: 200$ & 41 & 211 & 10,029 & 8 & $\begin{array}{c}83.67 \\
(70.34-92.66)\end{array}$ & $\begin{array}{c}97.94 \\
(97.65-98.21)\end{array}$ & $\begin{array}{c}16.27 \\
(11.94-21.42)\end{array}$ & $\begin{array}{c}99.92 \\
(99.84-99.97)\end{array}$ \\
\hline $1: 250^{*}$ & 43 & 245 & 9,995 & 6 & $\begin{array}{c}87.76 \\
(75.22-95.34)\end{array}$ & $\begin{array}{c}97.61 \\
(97.29-97.89)\end{array}$ & $\begin{array}{c}14.93 \\
(11.02-19.58)\end{array}$ & $\begin{array}{c}99.94 \\
(99.87-99.98)\end{array}$ \\
\hline $1: 300^{+}$ & 43 & 285 & 9,955 & 6 & $\begin{array}{c}87.76 \\
(75.22-95.34)\end{array}$ & $\begin{array}{c}97.22 \\
(96.88-97.53)\end{array}$ & $\begin{array}{c}13.11 \\
(9.65-17.25)\end{array}$ & $\begin{array}{c}99.94 \\
(99.87-99.98)\end{array}$ \\
\hline $1: 350$ & 43 & 335 & 9,905 & 6 & $\begin{array}{c}87.76 \\
(75.22-95.34)\end{array}$ & $\begin{array}{c}96.73 \\
(96.37-97.06)\end{array}$ & $\begin{array}{c}11.38 \\
(8.36-15.02)\end{array}$ & $\begin{array}{c}99.94 \\
(99.87-99.98)\end{array}$ \\
\hline $1: 500$ & 44 & 443 & 9,797 & 5 & $\begin{array}{c}89.80 \\
(77.76-96.56)\end{array}$ & $\begin{array}{c}95.67 \\
(95.26-96.06)\end{array}$ & $\begin{array}{c}9.03 \\
(6.64-11.94)\end{array}$ & $\begin{array}{c}99.95 \\
(99.88-99.98)\end{array}$ \\
\hline $1: 1,000$ & 47 & 786 & 9,454 & 2 & $\begin{array}{c}95.92 \\
(85.99-99.38)\end{array}$ & $\begin{array}{c}92.32 \\
(91.79-92.83)\end{array}$ & $\begin{array}{c}5.64 \\
(4.18-7.43)\end{array}$ & $\begin{array}{c}99.98 \\
(99.92-100.00)\end{array}$ \\
\hline
\end{tabular}

* Risk cut-off used to identify screen-positive women at National University Hospital. ${ }^{\dagger}$ Risk cut-off used to identify screen-positive women at Singapore General Hospital. NPV: negative predictive value; PPV: positive predictive value

Table II. Performance of first trimester screening in detecting trisomy 21 at different selected risk cut-offs $(\mathrm{n}=10,277$ ).

\begin{tabular}{|c|c|c|c|c|c|c|c|c|}
\hline \multirow{2}{*}{$\begin{array}{l}\text { Risk } \\
\text { cut-off }\end{array}$} & \multicolumn{4}{|c|}{ Absolute numbers } & \multicolumn{4}{|c|}{$\%$ ( $95 \%$ confidence interval) } \\
\hline & $\begin{array}{c}\text { True } \\
\text { positive }\end{array}$ & $\begin{array}{c}\text { False } \\
\text { positive }\end{array}$ & $\begin{array}{c}\text { True } \\
\text { negative }\end{array}$ & $\begin{array}{c}\text { False } \\
\text { negative }\end{array}$ & Sensitivity & Specificity & PPV & NPV \\
\hline $1: 150$ & 31 & 174 & 10,066 & 6 & $\begin{array}{c}83.78 \\
(67.98-93.77)\end{array}$ & $\begin{array}{c}98.30 \\
(98.03-98.54)\end{array}$ & $\begin{array}{c}15.12 \\
(10.51-20.77)\end{array}$ & $\begin{array}{c}99.94 \\
(99.87-99.98)\end{array}$ \\
\hline $1: 200$ & 32 & 211 & 10,029 & 5 & $\begin{array}{c}86.49 \\
(71.21-95.41)\end{array}$ & $\begin{array}{c}97.94 \\
(97.65-98.21)\end{array}$ & $\begin{array}{c}13.17 \\
(9.19-18.08)\end{array}$ & $\begin{array}{c}99.95 \\
(99.88-99.98)\end{array}$ \\
\hline $1: 250^{*}$ & 32 & 245 & 9,995 & 5 & $\begin{array}{c}86.49 \\
(71.21-95.41)\end{array}$ & $\begin{array}{c}97.61 \\
(97.29-97.89)\end{array}$ & $\begin{array}{c}11.55 \\
(8.04-15.92)\end{array}$ & $\begin{array}{c}99.95 \\
(99.88-99.98)\end{array}$ \\
\hline $1: 300^{+}$ & 32 & 285 & 9,955 & 5 & $\begin{array}{c}86.49 \\
(71.21-95.41)\end{array}$ & $\begin{array}{c}97.22 \\
(96.88-97.53)\end{array}$ & $\begin{array}{c}10.09 \\
(7.01-13.95)\end{array}$ & $\begin{array}{c}99.95 \\
(99.88-99.98)\end{array}$ \\
\hline $1: 350$ & 32 & 335 & 9,905 & 5 & $\begin{array}{c}86.49 \\
(71.21-95.41)\end{array}$ & $\begin{array}{c}96.73 \\
(96.37-97.06)\end{array}$ & $\begin{array}{c}8.72 \\
(6.04-12.09)\end{array}$ & $\begin{array}{c}99.95 \\
(99.88-99.98)\end{array}$ \\
\hline $1: 500$ & 33 & 443 & 9,797 & 4 & $\begin{array}{c}89.19 \\
(74.56-96.91)\end{array}$ & $\begin{array}{c}95.67 \\
(95.26-96.06)\end{array}$ & $\begin{array}{c}6.93 \\
(4.82-9.60)\end{array}$ & $\begin{array}{c}99.96 \\
(99.90-99.99)\end{array}$ \\
\hline $1: 1,000$ & 36 & 786 & 9,454 & 1 & $\begin{array}{c}97.30 \\
(85.79-99.55)\end{array}$ & $\begin{array}{c}92.32 \\
(91.79-92.83)\end{array}$ & $\begin{array}{c}4.38 \\
(3.09-6.01)\end{array}$ & $\begin{array}{c}99.99 \\
(99.94-100.00)\end{array}$ \\
\hline
\end{tabular}

* Risk cut-off used to identify screen-positive women at National University Hospital. ${ }^{\text {Risk }}$ cut-off used to identify screen-positive women at Singapore General Hospital. NPV: negative predictive value; PPV: positive predictive value

Therefore, the pregnancy loss rate after an invasive procedure was $0.3 \%$. We excluded the case of DiGeorge syndrome from the analysis of FTS performance, since this abnormality was not expected to be detected using FTS, thus resulting in a final sample size of 10,289.

The overall detection rate (sensitivity) of FTS for trisomies 21, 18 and 13 was $87.8 \%$, and the specificity was $97.6 \%$. The false positive rate was $2.4 \%$ and false negative rate was $0.06 \%$. The detection rate for trisomy 21 was $86.5 \%$ (32 out of 37 cases), while that for trisomy 18 and trisomy 13 was $90.9 \%$ (10 out of 11 cases) and $100.0 \%$ ( 1 out of 1 case), respectively. There was a total of 292 invasive procedures performed among all 10,289 cases that underwent FTS. The number of invasive procedures required to make a diagnosis of trisomies 21,18 or 13 was 6.5 (45 cases detected after 292 invasive procedures), while the number of invasive procedures required to make a diagnosis of trisomy 21 was 8.8 (33 cases detected after 292 invasive procedures). Table I shows the performance of FTS in detecting trisomies 21, 18 and 13 at different selected risk cut-offs; Table II shows the performance of FTS in detecting trisomy 21 at different risk cut-offs.

The performance of FTS in women aged $<35$ years and $\geq 35$ years is summarised in Table III. Its sensitivity for detecting trisomies 21, 18 and 13 in women aged $\geq 35$ years was found to be lower than that for detecting trisomies in women aged 
Table III. Performance of first trimester screening in detecting trisomies 21, 18 and 13, and trisomy 21 (Down syndrome) alone, stratified according to maternal age.

\begin{tabular}{|c|c|c|c|c|c|c|c|c|}
\hline \multirow{3}{*}{$\begin{array}{l}\text { Age } \\
\text { (yrs) }\end{array}$} & \multicolumn{8}{|c|}{$\%$ ( $95 \%$ confidence interval) } \\
\hline & \multicolumn{4}{|c|}{ Trisomies 21,18 and 13} & \multicolumn{4}{|c|}{ Trisomy 21} \\
\hline & Sensitivity & Specificity & PPV & NPV & Sensitivity & Specificity & PPV & NPV \\
\hline$<35$ & $\begin{array}{c}90.00 \\
(68.26-98.47)\end{array}$ & $\begin{array}{c}98.67 \\
(98.39-98.91)\end{array}$ & $\begin{array}{c}15.13 \\
(9.22-22.85)\end{array}$ & $\begin{array}{c}99.97 \\
(99.90-100.00)\end{array}$ & $\begin{array}{c}87.50 \\
(61.62-98.08)\end{array}$ & $\begin{array}{c}98.67 \\
(98.39-98.91)\end{array}$ & $\begin{array}{c}12.17 \\
(6.82-19.58)\end{array}$ & $\begin{array}{c}99.97 \\
(99.90-100.00)\end{array}$ \\
\hline$\geq 35$ & $\begin{array}{c}86.10 \\
(68.32-96.03)\end{array}$ & $\begin{array}{c}94.57 \\
(93.64-95.40)\end{array}$ & $\begin{array}{c}14.79 \\
(9.81-21.06)\end{array}$ & $\begin{array}{c}99.84 \\
(99.59-99.96)\end{array}$ & $\begin{array}{c}85.71 \\
(63.63-96.78)\end{array}$ & $\begin{array}{c}94.57 \\
(93.64-95.40)\end{array}$ & $\begin{array}{c}11.11 \\
(6.72-16.99)\end{array}$ & $\begin{array}{c}99.88 \\
(99.65-99.97)\end{array}$ \\
\hline
\end{tabular}

NPV: negative predictive value; PPV: positive predictive value

$<35$ years $(86.10 \%$ vs. $90.00 \%)$; however, this difference was not found to be statistically significant $(p=0.69)$. There was also a higher false positive rate for detecting trisomies in women aged $\geq 35$ years as compared to women aged $<35$ years $(5.43 \%$ vs. $1.33 \%$ ). The sensitivity of FTS for detecting trisomy 21 alone was also found to be lower in women aged $\geq 35$ than in women aged $<35$ years $(85.7 \%$ vs. $87.5 \%)$.

In the present study, there was a total of 833 cases with FTS risk scores that were greater than 1:1,000 (Table IV). Four cases of trisomy 21 had FTS risk scores between 1:251 and 1:1,000. Assuming that the cost of an NIPT is $\mathbf{S} \$ 1,000$, the total cost of offering NIPT to these 833 women would be $\$ \$ 833,000$, assuming a $100 \%$ uptake. Therefore, the cost incurred to identify one additional case of trisomy 21 would be $\$ \$ 208,250$. If we assume the cost of NIPT to be $\$ \$ 750$, the incremental cost incurred to identify one case of trisomy 21 would be lower (S\$156,187.50; Table V).

\section{DISCUSSION}

The findings of the present study confirm that FTS is an effective means of screening for trisomy 21 in Southeast Asian populations. The detection rate for trisomy 21 attained in the present study (i.e. $86.5 \%$ ) is comparable to the rates published for Caucasian ${ }^{(2,3,5,10,20)}$ and Chinese populations. ${ }^{(21-23}$ This may be attributed to our centres' strict adherence to the screening guidelines established by the FMF, ${ }^{(19)}$ which includes regular training and auditing of certified antenatal ultrasound sonographers. In addition, FTS attained $90.9 \%$ and $100.0 \%$ detection rates for trisomies 18 and 13 , respectively, in the present study. Both of these aneuploidies are associated with lethal malformations that are incompatible with life.

The overall false positive rate of FTS was $2.4 \%$ in the present study. This rate falls below the often-quoted range of $3.5 \%-5.0 \% .{ }^{(5)}$ The pregnancy loss rate after an invasive diagnostic procedure was $0.3 \%(1 / 298)$, which is lower than that often quoted in the literature. ${ }^{(24,25)}$ This may be because only the most experienced providers performed the procedures at the tertiary maternity centres in the present study.

We found that the detection rate for trisomy 21 in women aged $\geq 35$ years $(85.7 \%)$ was slightly lower than that of women aged $<35$ years $(87.5 \%)$. To the best of our knowledge, there is only one study in the literature that assessed the performance of FTS in women of different age groups - an observational study conducted in a Caucasian population. ${ }^{(7)}$ While the authors
Table IV. Number and cumulative number of cases, and Down syndrome cases according to different risk cut-off groups.

\begin{tabular}{lccc}
\hline $\begin{array}{l}\text { Risk cut-off } \\
\text { groups }\end{array}$ & $\begin{array}{c}\text { No. of } \\
\text { cases }\end{array}$ & $\begin{array}{c}\text { Cumulative } \\
\text { no. of cases }\end{array}$ & $\begin{array}{c}\text { No. of down } \\
\text { syndrome cases }\end{array}$ \\
\hline $1: 1-100$ & 167 & 167 & 28 \\
$1: 101-250$ & 121 & 288 & 4 \\
$1: 251-500$ & 199 & 487 & 1 \\
$1: 501-750$ & 153 & 640 & 2 \\
$1: 751-1,000$ & 193 & 833 & 1 \\
$1: 1,001-5,000$ & 2,731 & 3,564 & 0 \\
$1: 5,001-10,000$ & 2,779 & 6,343 & 1 \\
$1: 10,001-15,000$ & 2,089 & 8,432 & 0 \\
$1: 15,001-20,000$ & 1,366 & 9,798 & 0 \\
$1: 20,001$ and less & 491 & 10,289 & 0 \\
\hline
\end{tabular}

Note: Highlighted rows indicate cases with intermediate risk (i.e. 1: 251-1,000)

Table V. Incremental cost per case of trisomy 21 following noninvasive prenatal test (NIPT) in the first trimester screening intermediate risk group $(1: 251-1,000)$.

\begin{tabular}{lcc}
\hline $\begin{array}{l}\text { No. of additional } \\
\text { trisomy } \mathbf{2 1} \text { cases } \\
\text { identified }\end{array}$ & \multicolumn{2}{c}{$\begin{array}{c}\text { Incremental cost per trisomy } \\
\mathbf{2 1} \text { case } \mathbf{( S \mathbf { ~ } )}\end{array}$} \\
\cline { 2 - 3 } & $\begin{array}{c}\text { If cost of NIPT } \\
\text { is } \mathbf{S 1 , 0 0 0}\end{array}$ & $\begin{array}{c}\text { If cost of } \mathbf{N I P T} \\
\text { is } \mathbf{S} \mathbf{\$ 7 5 0}\end{array}$ \\
\hline 4 & $208,250.00$ & $156,187.50$ \\
3 & $277,666.67$ & $208,250.00$ \\
2 & $416,500.00$ & $312,375.00$ \\
1 & $833,000.00$ & $624,750.00$ \\
\hline
\end{tabular}

reported a significantly poorer detection rate in younger women $(74.0 \%)$, the reported detection rate for older women $(87.0 \%)$ was comparable to that of the present study. The study was conducted between 2002 and 2008, and it primarily compared women aged $<35$ with a selected, much smaller control group of women aged $\geq 35$ years. The screening results of that study were also calculated using a different program - the authors used the Perkin Elmer Lifecycle ${ }^{\mathrm{TM}}$ algorithm, ${ }^{(7)}$ while we adopted the FMF software.

In the present study, the number of invasive tests per case of trisomy 21 was 9.2 (14 cases detected for 129 procedures performed) in women aged $<35$ years and 8.6 (19 cases detected for 163 procedures performed) in women aged $\geq 35$ years. FTS was found to have similar efficacy in women aged $<35$ years and $\geq 35$ years in the present study, which consisted of a large study population. Among women with intermediate risk (1:250$1,000)$ the number of invasive tests per case of trisomy 21 was 
Table VI. Comparison of the age distribution of the study population with that of the delivery population in NUH.

\begin{tabular}{lcc}
\hline $\begin{array}{l}\text { Age } \\
\text { group } \\
(\mathbf{y r})\end{array}$ & \multicolumn{2}{c}{ No. of women (\%) } \\
\cline { 2 - 3 } & $\begin{array}{c}\text { Study population } \\
(\mathbf{n}=\mathbf{1 0 , 2 9 5 )}\end{array}$ & $\begin{array}{c}\text { All deliveries at } \\
\mathbf{N U H}(\mathbf{n}=\mathbf{2 3 , 5 6 0 )}\end{array}$ \\
\hline$<30$ & $3,125(30.4)$ & $14,871(63.1)$ \\
$30-34$ & $4,488(43.6)$ & $5,175(22.0)$ \\
$35-39$ & $2,385(23.2)$ & $2,976(12.6)$ \\
$\geq 40$ & $297(2.9)$ & $538(2.3)$ \\
\hline
\end{tabular}

NUH: National University Hospital

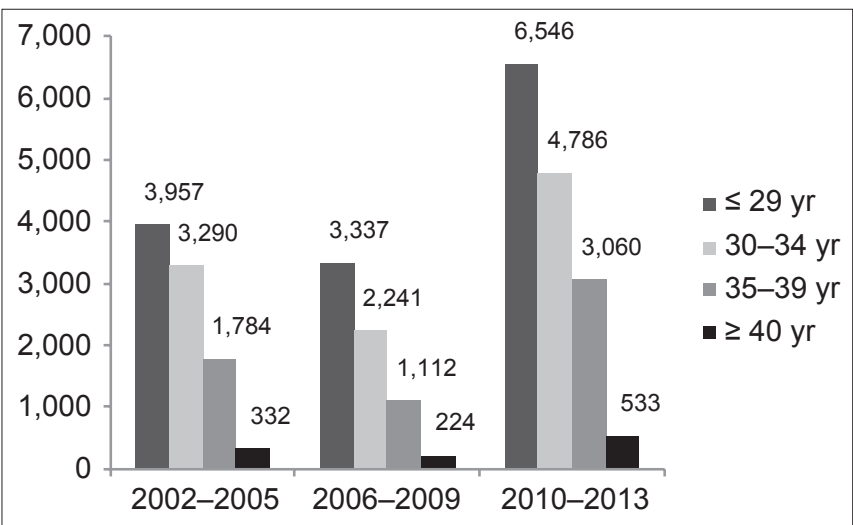

Fig. 2 Average number of deliveries in National University Hospital from 2002-2013, over four-year periods and according to the various age groups $(n=27,399)$.

13.5 ( 2 cases detected for 27 procedures performed). The two cases of trisomy 21 were in women aged $>35$ years. Therefore, it was more likely for women with intermediate risk, regardless of age, to be subjected to an invasive procedure, which may result in an increased risk of pregnancy loss.

There was a higher proportion of women in our study population who were aged $35-39$ years $(23.2 \%)$ as compared to the total delivery population at NUH (12.6\%) (Table VI). This is likely a reflection of the perceived importance of screening for chromosomal aneuploidies among mothers of advanced maternal age. In developed countries, including Singapore, the proportion of women of advanced maternal age is on a rising trend. At $\mathrm{NUH}$, this proportion rose from an average of $19.3 \%$ in 2006-2009 to $24.1 \%$ in 2010-2013 (Fig. 2). It is likely that we will observe a global increase in the uptake of FTS and a possible resultant concomitant rise in the number of invasive diagnostic tests performed.

It may be advantageous to offer the high-risk group NIPT using cfDNA to reduce the risk of iatrogenic fetal loss. Using a combined false positive rate of $0.43 \%$ for trisomies 21,18 and $13,{ }^{(14)}$ we would expect the number of false positive in the group of women with high-risk screening results (i.e. risk $>1: 250$ ) to be reduced from 245 to 2 , thus reducing the number of unnecessary invasive procedures by 120 -fold. In a study by Gil et al, the authors suggested that NIPT could be offered as a contingent screen following FTS results. ${ }^{(14)}$ They proposed that women with intermediate risk (defined as $1: 11-2,500$ in that study) could also be offered cfDNA analysis. ${ }^{(14)}$ We suggest that the use of risk scores between 1:251 and 1:1,000 may be a more cost-effective threshold. In the present study, we observed six false negative cases (five trisomy 21 and one trisomy 18). If the uptake of NIPT within the group with a FTS risk of $1: 251-1,000$ was $100 \%$ with a minimum sensitivity of $92 \%$ (based on the detection rate for trisomy 13), ${ }^{(14)}$ we would expect to detect an additional four cases of aneuploidy. That is, we would miss one case of trisomy 18 (risk 1:1,066 by FTS) and one case of trisomy 21 (risk $1: 8,801$ by FTS). Although widening the threshold to $1: 251-1,500$ would allow identification of the false negative trisomy 18 case, the trisomy 21 case with 1:8,801 risk would still not be detected using contingent screening. As sequencing technology improves and its cost decreases, it is likely that NIPT will be incorporated into routine screening for fetal aneuploidy in all pregnant women in the future.

The present study was not without limitations. One such limitation was the inability to obtain karyotype confirmation for pregnancies that ended in spontaneous miscarriage, and intrauterine fetal demise or termination. In other words, the prevalence of trisomies 21, 18 and 13 may have been underestimated in the present study. Besides that, some studies have shown that using the FTS algorithm to calculate the gestation-specific multiples of the medians (MoMs) of free $\beta$-hCG and PAPP-A levels in Chinese populations would result in significantly higher values than if these MoMs were calculated using a Chinese-specific formula. ${ }^{26,27)}$ If this adjustment was taken into account in the present study, there is a possibility that the screen-positive rate would have been increased. However, as the MoMs of biochemical markers in patients of other ethnicities, which comprised more than $20 \%$ of our study population, have not been examined in large cohort studies, the effect of such an adjustment in the risk calculation is still unclear.

The total delivery rate of both tertiary maternity centres is approximately 4,000 per year. About $50 \%$ of the patients who were screened at our centres chose to deliver in the same centre. At the moment, although there is no established computerised system, we rely on a closed feedback loop system that requires any trisomy 21 cases delivered outside the institution where screening was performed to be reported back to the screening institution.

To the best of our knowledge, the present study is the first in Singapore to assess the performance of FTS in women of different ages and the incremental costs associated with offering NIPT to women with intermediate or high risk following FTS. From the current published literature, it appears that the performance of FTS in ethnic groups such as Malays has yet to be examined. The high sensitivity and low false positive rates attained in the present study may be attributed to the centres' high standards of quality control that are in place for first trimester ultrasound examination and their compliance to regular external quality validation by FMF. Robust delivery outcome data was also easily obtained because the databases at both centres were well organised and there was close communication between the centres and their cytogenetic laboratories, which keep records of live births with trisomy 21 .

To conclude, the results of the present study provide supporting evidence that clinicians in Singapore should recommend FTS as a first-line screening for trisomy 21, regardless of maternal age. Older women (i.e. aged $\geq 35$ years) should be 
informed that the false positive rate of FTS is higher for them than for younger women. Women who have intermediate risk are more likely to undergo invasive diagnostic testing. These two groups of women should be offered the alternative of NIPT to further stratify their risk.

\section{ACKNOWLEDGEMENT}

We would like to acknowledge Ms Dawn Chia from the Fetal Care Centre, National University Hospital, Singapore, for her help in collating the centre's FTS results.

\section{REFERENCES}

1. Wapner R, Thom E, Simpson JL, et al; First Trimester Maternal Serum Biochemistry and Fetal Nuchal Translucency Screening (BUN) Study Group. First-trimester screening for trisomies 21 and 18. N Engl J Med 2003; 349:1405-13.

2. Malone FD, Canick JA, Ball RH, et al; First- and Second-Trimester Evaluation of Risk (FASTER) Research Consortium. First-trimester or secondtrimester screening, or both, for Down's syndrome. N Engl J Med 2005; 353:2001-11.

3. Kagan KO, Wright D, Baker A, Sahota D, Nicolaides KH. Screening for trisomy 21 by maternal age, fetal nuchal translucency thickness, free beta-human chorionic gonadotropin and pregnancy-associated plasma protein-A. Ultrasound Obstet Gynecol 2008; 31:618-24.

4. Avgidou K, Papageorghiou A, Bindra R, Spencer K, Nicolaides KH. Prospective first-trimester screening for trisomy 21 in 30,564 pregnancies. Am J Obstet Gynecol 2005; 192:1761-7.

5. Kagan KO, Etchegaray A, Zhou Y, Wright D, Nicolaides KH. Prospective validation of first-trimester combined screening for trisomy 21 . Ultrasound Obstet Gynecol 2009; 34:14-8.

6. Spencer K, Spencer CE, Power M, Dawson C, Nicolaides KH. Screening for chromosomal abnormalities in the first trimester using ultrasound and maternal serum biochemistry in a one-stop clinic: a review of three years prospective experience. BJOG 2003; 110:281-6.

7. Peuhkurinen S, Laitinen P, Ryynanen M, Marttala J. First trimester Down syndrome screening is less effective and the number of invasive procedures is increased in women younger than 35 years of age. J Eval Clin Pract 2013 ; 19:324-6.

8. Chou $\mathrm{CY}, \mathrm{Hsieh} \mathrm{FJ}$, Cheong ML, et al. First-trimester Down syndrome screening in women younger than 35 years old and cost-effectiveness analysis in Taiwan population. J Eval Clin Pract 2009; 15:789-96.

9. Bindra R, Heath V, Liao A, Spencer K, Nicolaides KH. One-stop clinic for assessment of risk for trisomy 21 at 11-14 weeks: a prospective study of 15030 pregnancies. Ultrasound Obstet Gynecol 2002; 20:219-25.

10. Hadlow NC, Hewitt BG, Dickinson JE, Jacoby P, Bower C. Communitybased screening for Down's Syndrome in the first trimester using ultrasound and maternal serum biochemistry. BJOG 2005; 112:1561-4.

11. Bianchi DW, Platt LD, Goldberg JD, et al; MatErnal Blood IS Source to
Accurately diagnose fetal aneuploidy (MELISSA) Study Group. Genomewide fetal aneuploidy detection by maternal plasma DNA sequencing. Obstet Gynecol 2012; 119:890-901.

12. Chiu RW, Akolekar R, Zheng YW, et al. Non-invasive prenatal assessment of trisomy 21 by multiplexed maternal plasma DNA sequencing: large scale validity study. BMJ 2011; 342:c7401.

13. Norton ME, Brar H, Weiss J, et al. Non-Invasive Chromosomal Evaluation (NICE) Study: results of a multicenter prospective cohort study for detection of fetal trisomy 21 and trisomy 18. Am J Obstet Gynecol 2012; 207:137. e1-8.

14. Gil MM, Akolekar R, Quezada MS, Bregant B, Nicolaides KH. Analysis of cell-free DNA in maternal blood in screening for aneuploidies: metaanalysis. Fetal Diagn Ther 2014; 35:156-73.

15. Soothill PW. Non-invasive Prenatal Testing for Chromosomal Abnormalities using Maternal Plasma DNA. Scientific Impact Paper No 15. March 2014.

16. Gregg AR, Gross SJ, Best RG, et al. ACMG statement on noninvasive prenatal screening for fetal aneuploidy. Genet Med 2013; 15:395-8.

17. American College of Obstetricians and Gynecologists Committee on Genetics. Committee Opinion No. 545: Noninvasive prenatal testing for fetal aneuploidy. Obstet Gynecol 2012; 120:1532-4.

18. Benn P, Borell A, Chiu R, et al. Position statement from the Aneuploidy Screening Committee on behalf of the Board of the International Society for Prenatal Diagnosis. Prenat Diagn 2013; 33:622-9.

19.Fetal Medicine Foundation guidelines for First Trimester Screening. Available at: http://aogm.org.mo/assets/Uploads/aogm/FMF-files/Guide-forthe-First-Trimester-Screening-program.pdf. Accessed December 15, 2014.

20. Stenhouse EJ, Crossley JA, Aitken DA, et al. First-trimester combined ultrasound and biochemical screening for Down syndrome in routine clinical practice. Prenat Diagn 2004; 24:774-80.

21. Leung TY, Chan LW, Leung TN, et al. First-trimester combined screening for trisomy 21 in a predominantly Chinese population. Ultrasound Obstet Gynecol 2007; 29:14-7.

22. Leung TY, Chan LW, Law LW, et al. First trimester combined screening for Trisomy 21 in Hong Kong: outcome of the first 10,000 cases. J Matern Fetal Neonatal Med 2009; 22:300-4.

23. Yeo GS, Lai FM, Wei $X$, et al. Validation of first trimester screening for trisomy 21 in Singapore with reference to performance of nasal bone. Fetal Diagn Ther 2012; 32:166-70.

24. Kuppermann M, Nease RF, Learman LA, et al. Procedure-related miscarriages and Down syndrome-affected births: implications for prenatal testing based on women's preferences. Obstet Gynecol 2000; 96:511-6.

25. Tabor A, Vestergaard CH, Lidegaard Ø. Fetal loss rate after chorionic villus sampling and amniocentesis: an 11-year national registry study. Ultrasound Obstet Gynecol 2009; 34:19-24.

26. Leung TY, Spencer K, Leung TN, Fung TY, Lau TK. Higher median levels of free beta-hCG and PAPP-A in the first trimester of pregnancy in a Chinese ethnic group. Implication for first trimester combined screening for Down's syndrome in the Chinese population. Fetal Diagn Ther 2006; 21:140-3.

27. Sahota DS, Leung TY, Fung TY, et al. Medians and correction factors for biochemical and ultrasound markers in Chinese women undergoing first-trimester screening for trisomy 21. Ultrasound Obstet Gynecol 2009; 33:387-93. 